\title{
Benefit of adjunct corticosteroids for community-acquired pneumonia in diabetic patients
}

\author{
Milica Popovic $^{1} \cdot$ Claudine A. Blum $^{1,2} \cdot$ Nicole Nigro $^{1} \cdot$ Beat Mueller $^{2}$. \\ Philipp Schuetz ${ }^{2}$ Mirjam Christ-Crain ${ }^{1}$
}

Received: 11 May 2016 / Accepted: 10 August 2016/Published online: 10 September 2016

(C) Springer-Verlag Berlin Heidelberg 2016

\begin{abstract}
Aims/hypothesis We have recently shown that adjunct prednisone shortens the time taken to reach clinical stability (time to clinical stability, TTCS) in patients with community-acquired pneumonia (CAP). Considering the hyperglycaemic effects of prednisone, there are concerns about the efficacy and safety of this therapy for diabetic patients with CAP. Our objective was to evaluate whether diabetes and/or hyperglycaemia on admission to hospital has an influence on the effect of corticosteroids on outcome in a well-defined cohort of patients with CAP.

Methods This is a preplanned subanalysis of a prospective randomised, double-blind placebo-controlled multicentre trial. Patients aged 18 years or older with CAP were eligible and were recruited from seven tertiary care hospitals in Switzerland within $24 \mathrm{~h}$ of presentation. Patients were randomised (1:1 ratio) to receive either $50 \mathrm{mg}$ of prednisone daily for 7 days or placebo. Allocation was concealed with a prespecified computer-generated randomisation list. Patients,
\end{abstract}

Milica Popovic and Claudine Blum contributed equally to this paper.

Philipp Schuetz and Mirjam Christ-Crain are joint senior authors.

Electronic supplementary material The online version of this article (doi:10.1007/s00125-016-4091-4) contains peer-reviewed but unedited supplementary material, which is available to authorised users.

Mirjam Christ-Crain

mirjam.christ@usb.ch

1 Endocrinology, Diabetology and Metabolism, Department of Internal Medicine and Department of Clinical Research, University Hospital Basel, Petersgraben 4, 4031 Basel, Switzerland

2 Medical University Clinic, Departments of Internal and Emergency Medicine and Department of Endocrinology, Diabetology and Metabolism, Kantonsspital Aarau, Aarau, Switzerland treating physicians, investigators and data assessors were masked to treatment allocation. The primary endpoint was TTCS; secondary endpoints were length of stay, mortality, duration of antibiotic treatment, CAP complications and new insulin requirement at day 30. Furthermore, we analysed whether these endpoints were influenced by a glycaemic dysregulation during the study time.

Results Of 802 patients randomised ( $n=402$ in the prednisone, $n=400$ in the placebo group), 726 patients were treated per protocol and included in this analysis $(n=362$ in the prednisone, $n=364$ in the placebo group). Nineteen per cent of 726 patients had diabetes mellitus $(n=66$ in the prednisone group, $n=72$ in the placebo group). Adjunct prednisone shortened TTCS in diabetic and non-diabetic patients (HR 1.65 [95\% CI 1.16, 2.35], $p=0.007 ; 1.30$ [95\% CI 1.10, 1.53], $p=0.002$ ) with no evidence for effect modification by diabetes in interaction analysis $(p=0.44)$. No difference was found in other clinically relevant endpoints. Although adjunct prednisone was associated with glycaemic dysregulation, this did not translate into worse clinical outcomes in either group, and there was no difference in secondary endpoints.

Conclusions/interpretation The benefit of adjunct prednisone in CAP patients is also valid for those with diabetes or hyperglycaemia on admission. Hyperglycaemia in diabetic patients or due to adjunct prednisone did not have a negative effect on outcome.

Trial registration ClinicalTrials.gov NCT00973154

Funding This study was supported by a grant from the Swiss National Foundation and by the Nora van Meeuwen Häfliger Stiftung and the Gottfried Julia Bangerter-Rhyner Stiftung.

Keywords Community-acquired pneumonia . Corticosteroids · Diabetes mellitus $\cdot$ Hyperglycaemia $\cdot$ Pneumonia $\cdot$ Prednisone $\cdot$ Time to clinical stability 


\section{Abbreviations \\ CAP Community-acquired pneumonia \\ ICU Intensive care unit \\ PSI Pneumonia severity index \\ TTCS Time to clinical stability}

\section{Introduction}

Diabetes mellitus is a prevalent comorbidity in patients with community-acquired pneumonia (CAP). It is associated with adverse outcomes of CAP, such as increased mortality [1-5], prolonged length of hospital stay [2, 6], more severe illness [3, $6,7]$ and an increased rate of complications [3,6]. Similar to a general CAP population, higher CAP severity scores (e.g. PSI [pneumonia severity index], CURB65 [confusion, blood urea nitrogen, respiratory rate, low blood pressure, age $\geq 65$ years] and A-DROP [age, dehydration, respiratory failure, orientation disturbance, low blood pressure] [1-3, 8-10]), time to antibiotics, early complications, advanced age, multilobar infiltrates and comorbidities predict death in a diabetic cohort with CAP [5, 11]. Diabetes-specific risk factors predicting outcome include persistent hyperglycaemia during hospitalisation and presence of long-term diabetes complications like retinopathy and nephropathy $[3,10,12]$. In diabetic patients with any infectious disease, $\mathrm{HbA}_{1 \mathrm{c}}$ level and diabetes duration have been shown to be additional diabetes-specific predictors for infection-related death [5, 13]. Data for these risk factors in patients with CAP in particular are missing.

Interestingly, the predictive value of initial serum glucose for outcome of CAP in diabetic patients is debated [1, 5, 12, 14]. Nonetheless, in non-diabetic individuals with CAP, hyperglycaemia upon admittance is an unambiguous, stressrelated predictor for adverse outcome $[1,12,15]$.

We have recently shown that adjunct corticosteroids as compared with placebo in a general CAP population shortens the time to reach clinical stability (time to clinical stability, TTCS) and duration of hospital stay [16, 17]. Herein, our aim was to evaluate whether pre-existing diabetes and/or hyperglycaemia had an influence on the effect of corticosteroids on TTCS and other endpoints in this well-defined cohort of patients with CAP from a previous multicentre study.

\section{Methods}

Study design and participants This is a preplanned subanalysis of a prospective randomised, double-blind, placebo-controlled multicentre trial, in which the additive effect of prednisone in CAP was investigated. The main study demonstrated the benefit of corticosteroids in CAP, with a reduction in TTCS and duration of hospital stay [17].
Study details have been published [18]. Briefly, upon admission to hospital, consecutive patients with CAP were randomised to receive $50 \mathrm{mg}$ of prednisone for 7 days or to receive placebo. Inclusion criteria were age 18 years or older and hospital admission with CAP [19]. Exclusion criteria were permanent inability for informed consent, active intravenous drug use, acute burn injury, gastrointestinal bleeding within the past 3 months, known adrenal insufficiency, a condition requiring more than $0.5 \mathrm{mg} / \mathrm{kg}$ per day prednisone equivalent, pregnancy, breastfeeding and severe immunosuppression [17].

The primary objective of this analysis was to investigate whether the effect of corticosteroids on TTCS is modified by the presence of diabetes mellitus. Diabetes mellitus was defined as having pre-existing diabetes, ascertained by medical records.

Secondary objectives were as follows: (1) effect modification by the presence of initial hyperglycaemia, defined as initial (first) blood glucose measurement $>11.0 \mathrm{mmol} / \mathrm{l}$ on day 1 (i.e. before start of study medication), irrespective of diabetes diagnosis or administration of glucose-lowering agents and (2) the effect of corticosteroids on blood glucose values during the time of study and their influence on outcome. The primary endpoint for primary and secondary objectives was TTCS, defined as time to stabilisation of vital signs at two consecutive measurements $\geq 12 \mathrm{~h}$ apart. Secondary endpoints included time to effective hospital discharge, all-cause mortality, total and intravenous duration of antibiotic treatment, CAP complications (including recurrence, acute respiratory distress syndrome, empyema, nosocomial infections until day 30 , severe adverse events possibly related to CAP, intensive care unit [ICU] stay, re-admission to hospital) and new insulin requirement at day 30 .

The conduct of the trial adhered to the declaration of Helsinki and Good Clinical Practice Guidelines, and ethical committees of all participating hospitals approved the study before patient recruitment. The trial was registered with ClinicalTrials.gov (registration no. NCT00973154).

Procedures Informed consent was obtained within $24 \mathrm{~h}$ of admission to hospital; thereafter, patients started receiving study medication. Study nurses assessed patients for clinical stability (defined as normalisation of body temperature, oxygen saturation, blood pressure and heart rate) [17] every $12 \mathrm{~h}$ during hospital stay. All patients were treated according to published CAP guidelines [20]. Baseline data included medical history, relevant comorbidities, clinical variables relating to pneumonia and all variables required for the calculation of the PSI [21]. In diabetic individuals, the type of diabetes, type of on-going treatment (oral, insulin, diet only) and $\mathrm{HbA}_{1 \mathrm{c}}$ levels (in $60 \%$ of diabetic patients) were assessed on admission. In all patients, glucose measurements were performed at 08:00, 12:00, 18:00 and 20:00 hours on days $1,3,5$ and 7 to 
screen for corticosteroid-induced hyperglycaemia. All blood glucose measurements were based on fingerstick tests and explicitly included at least one glucose measurement scheduled $2 \mathrm{~h}$ postprandially. The doctors and nurses administering treatments were instructed to perform daily glucose measurements if the screening glucose levels showed relevant hyperglycaemia and to consider starting or increasing antihyperglycaemic treatment if indicated. Structured follow-up telephone interviews for secondary outcomes after discharge were done on day 30 .

Statistical analysis To analyse the effect of corticosteroids in diabetic patients and patients with hyperglycaemia, the perprotocol population was subdivided as follows: (1) diabetic patients and non-diabetic patients and (2) patients with and without initial hyperglycaemia, irrespective of diabetes diagnosis. For the primary endpoint, we performed Cox regression models for TTCS and included interaction terms. Significant results in interaction analysis provide evidence for effect modification. Therefore, interaction $p$ values $\geq 0.05$ indicate no significant difference regarding the effect of prednisone in the respective subgroup compared with the entire study population, while $p<0.05$ suggests that the subgroup differs from the entire study population regarding the effect of prednisone. Secondary endpoints were compared between the two arms by the Mann-Whitney test for continuous data or linear regression, $\chi^{2}$ tests or Fisher's exact test, respectively, or binomial/ Poisson regression for binary/count data, and the logrank test or Cox regression for time-to-event data. For all endpoints, estimates of the effect size and corresponding 95\% CIs were provided.

The effect of corticosteroids on glucose levels was assessed by comparing the following variables between the prednisone and placebo group: (1) mean glucose value during study time; (2) SD of glucose values as a surrogate marker for glycaemic variability during study time and (3) difference in outcome according to glucose values. The mean glucose value during the study period was calculated for every patient using the mean of all available blood glucose values measured during the study time. For every patient, we calculated the SD of the mean glucose value during the study time as a surrogate marker for glucose variability $[22,23]$.

Further, to investigate the influence of glycaemia on outcome, we analysed the influence of higher mean glucose value and higher glycaemic variability on outcomes in different subgroups (e.g. patients receiving prednisone vs placebo; diabetic vs non-diabetic patients). First, we adjusted these data for PSI. Second, we adjusted for PSI and additional insulin requirement.

\section{Results}

Baseline characteristics In this study, 802 eligible patients were randomly assigned to receive either prednisone or placebo (Fig. 1). After blinded post-randomisation exclusion of protocol violators and patients retrospectively not meeting eligibility criteria, the per-protocol population consisted of 362 treated with prednisone and 365 patients receiving placebo.
Fig. 1 Patient flow by treatment group

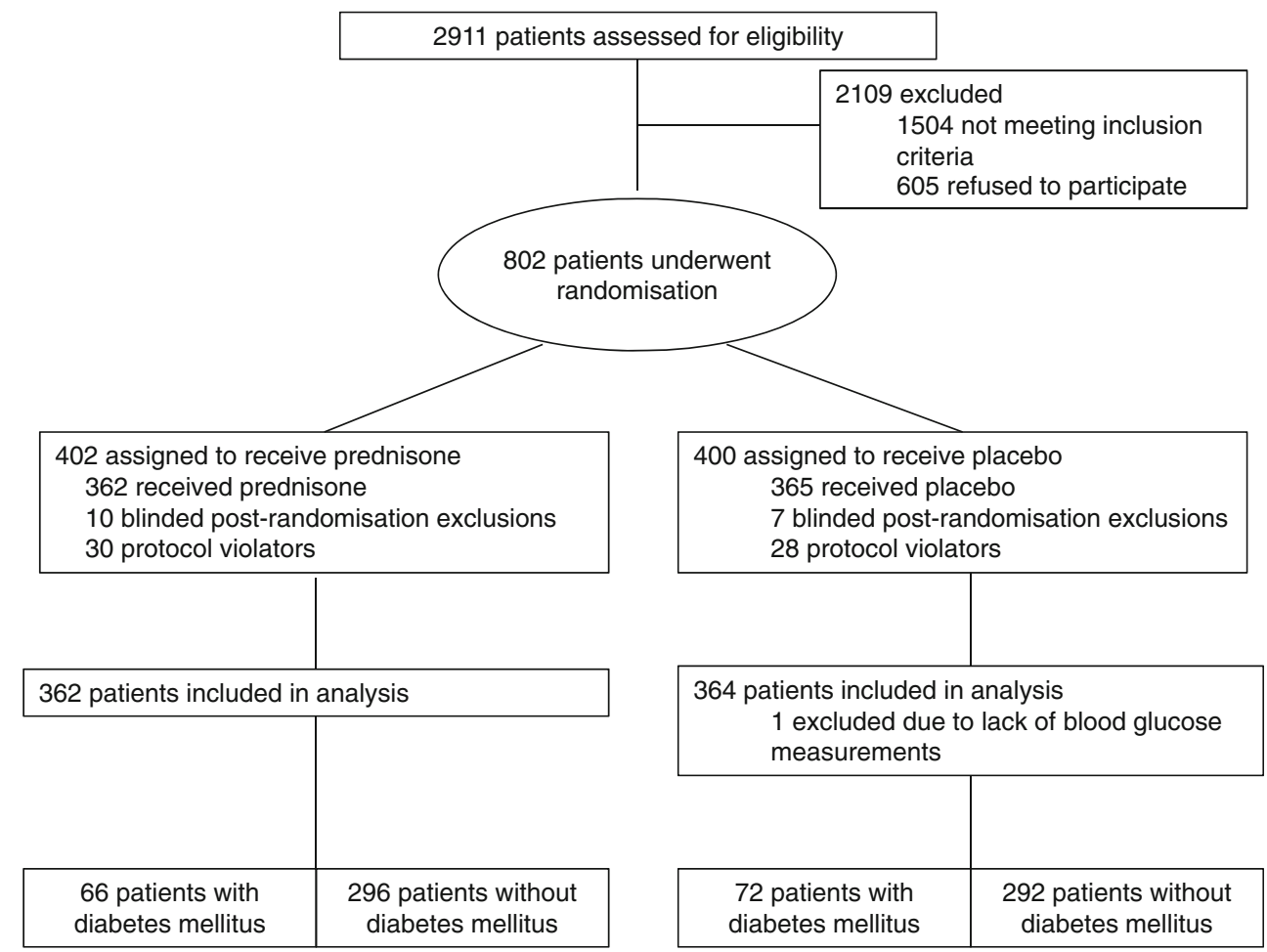


These groups were further subdivided into patients with and without pre-existing diabetes mellitus. In the non-diabetic placebo group, one patient had to be excluded from the analysis due to lack of blood glucose measurements.

Table 1 shows the baseline characteristics of diabetic and non-diabetic patients in the treatment subgroups. The mean age of diabetic patients was 75 years, and $73 \%$ were men. Sixty-seven per cent of diabetic patients were in high-risk PSI classes IV and V, as compared with $45 \%$ of non-diabetic patients, resulting in a higher PSI score in diabetic patients. A greater proportion of diabetic patients had comorbidities compared with non-diabetic patients, with a significantly higher rate of heart failure and renal insufficiency. Within the diabetic group, $32 \%$ of the patients in the prednisone and $33 \%$ in the placebo group had insulin pre-treatment. Mean initial glucose was $8.5 \mathrm{mmol} / \mathrm{l}$ in diabetic patients and $6.8 \mathrm{mmol} / \mathrm{l}$ in nondiabetic patients. None of the patients treated with prednisone experienced diabetic ketoacidosis.

Effect of corticosteroids on outcome in diabetic vs nondiabetic patients First, we investigated TTCS in both groups, with HR $>1.0$ corresponding to faster TTCS. Adjunct prednisone shortened TTCS in both diabetic and non-diabetic individuals, as shown in Table 2 (HR [95\% CI] 1.65 [1.16, 2.35] vs $1.30[1.10,1.53])$, with no evidence for effect modification in interaction analysis $(p=0.44)$. With regards to all-cause mortality at day 30 , there was no significant difference with adjunct prednisone between diabetic and non-diabetic patients

Table 1 Baseline characteristics and clinical variables of participants (per-protocol population)

\begin{tabular}{|c|c|c|c|c|c|c|c|c|c|}
\hline \multirow[t]{2}{*}{ Characteristic/variable } & \multicolumn{4}{|c|}{ Diabetic patients $(n=138)$} & \multicolumn{4}{|c|}{ Non-diabetic patients $(n=588)$} & \multirow{2}{*}{$\begin{array}{l}p \\
\text { value }^{\mathrm{a}}\end{array}$} \\
\hline & All & $\begin{array}{l}\text { Prednisone } \\
(n=66)\end{array}$ & $\begin{array}{l}\text { Placebo } \\
(n=72)\end{array}$ & $\begin{array}{l}p \\
\text { value }\end{array}$ & All & $\begin{array}{l}\text { Prednisone } \\
(n=296)\end{array}$ & $\begin{array}{l}\text { Placebo } \\
(n=292)\end{array}$ & $\begin{array}{l}p \\
\text { value }\end{array}$ & \\
\hline Male sex & $100(72.5)$ & $49(74)$ & $51(71)$ & 0.65 & $351(59.7)$ & $174(58.8)$ & $177(60.6)$ & 0.65 & 0.005 \\
\hline Age, years & $74.7 \pm 10.6$ & $74.9 \pm 10.4$ & $74.5 \pm 10.8$ & 0.82 & $68.4 \pm 18.3$ & $69.2 \pm 18.6$ & $67.6 \pm 18.0$ & 0.26 & $<0.001$ \\
\hline Body temperature, ${ }^{\circ} \mathrm{C}$ & $37.68 \pm 0.97$ & $37.7 \pm 1.0$ & $37.7 \pm 1.0$ & 0.84 & $37.61 \pm 0.96$ & $37.6 \pm 1.0$ & $37.6 \pm 1.0$ & 0.90 & 0.42 \\
\hline Systolic blood pressure, $\mathrm{mmHg}$ & $129.88 \pm 21.71$ & $129.5 \pm 22.8$ & $130.2 \pm 20.9$ & 0.86 & $124.91 \pm 20.96$ & $124.5 \pm 20.8$ & $125.2 \pm 21.2$ & 0.67 & 0.013 \\
\hline Heart rate, beats per min & $82.87 \pm 16.55$ & $84.6 \pm 16.1$ & $81.3 \pm 16.9$ & 0.23 & $85.27 \pm 17.43$ & $85.2 \pm 17.4$ & $85.3 \pm 17.5$ & 0.95 & 0.14 \\
\hline Respiratory rate, breaths per min & $21.82 \pm 5.46$ & $21.9 \pm 4.7$ & $21.7 \pm 6.0$ & 0.86 & $21.00 \pm 5.11$ & $20.8 \pm 5.0$ & $21.2 \pm 5.2$ & 0.34 & 0.12 \\
\hline $\mathrm{SaO}_{2}, \%$ & $93.59 \pm 3.69$ & $93.0 \pm 3.8$ & $94.1 \pm 3.5$ & 0.90 & $93.96 \pm 3.91$ & $94.1 \pm 3.9$ & $93.9 \pm 4.0$ & 0.57 & 0.31 \\
\hline Confusion & $13(9.4)$ & $6(9)$ & $7(10)$ & 0.90 & $33(5.6)$ & $15(5.1)$ & $18(6.2)$ & 0.56 & 0.10 \\
\hline \multicolumn{10}{|l|}{ Laboratory values } \\
\hline Procalcitonin, ng/ml & $5.2 \pm 15.5$ & $4.9 \pm 12.3$ & $5.5 \pm 18.1$ & 0.83 & $5.0 \pm 19.0$ & $5.1 \pm 19.8$ & $4.9 \pm 18.2$ & 0.93 & 0.91 \\
\hline C-reactive protein, $\mathrm{mg} / \mathrm{l}$ & $166.65 \pm 108.37$ & $168.7 \pm 105.1$ & $164.8 \pm 112.0$ & 0.83 & $175.681 \pm 118.29$ & $171.4 \pm 112.9$ & $180.0 \pm 123.6$ & 0.38 & 0.42 \\
\hline $\begin{array}{l}\text { White-blood-cell count, } \\
\text { no. of cells per } \mu \mathrm{l}\end{array}$ & $12.45 \pm 5.86$ & $12.4 \pm 6.9$ & $12.5 \pm 4.8$ & 0.95 & $12.90 \pm 6.34$ & $13.2 \pm 6.4$ & $12.6 \pm 6.3$ & 0.27 & 0.45 \\
\hline \multicolumn{10}{|l|}{ PSI } \\
\hline Class I & $2(1.4)$ & $1(2)$ & $1(1)$ & 0.92 & $83(14.1)$ & $42(14.2)$ & $41(14.0)$ & 0.22 & $<0.001$ \\
\hline Class II & $16(11.6)$ & $9(14)$ & $7(10)$ & & $119(20.2)$ & 59 (19.9) & $60(20.5)$ & & \\
\hline Class III & 27 (19.6) & $13(20)$ & $14(19)$ & & $122(20.7)$ & $51(17.2)$ & $71(24.3)$ & & \\
\hline Class IV & $72(52.2)$ & $32(48)$ & $40(56)$ & & $189(32.1)$ & $105(35.5)$ & $84(28.8)$ & & \\
\hline Class V & $21(15.2)$ & $11(17)$ & $10(14)$ & & $75(12.8)$ & $39(13.2)$ & $36(12.3)$ & & \\
\hline Total PSI score, points & $104.7 \pm 29.6$ & $105.3 \pm 31.5$ & $104.2 \pm 27.9$ & 0.82 & $87.5 \pm 37.6$ & $89.5 \pm 38.9$ & $85.4 \pm 36.2$ & 0.19 & $<0.001$ \\
\hline \multicolumn{10}{|l|}{ Comorbidities } \\
\hline $\begin{array}{l}\text { Chronic obstructive pulmonary } \\
\text { disease }\end{array}$ & $27(19.6)$ & $13(20.0)$ & $13(18.1)$ & 0.81 & $98(16.7)$ & $57(19.3)$ & $39(13.4)$ & 0.053 & 0.42 \\
\hline Heart failure & $39(28.3)$ & $19(29)$ & $20(28)$ & 0.90 & $91(15.5)$ & $54(18.2)$ & 37 (12.7) & 0.064 & $<0.001$ \\
\hline Cerebrovascular disease & $17(12.3)$ & $9(14)$ & $8(11)$ & 0.65 & $44(7.5)$ & $23(7.8)$ & $21(7.2)$ & 0.80 & 0.066 \\
\hline Renal insufficiency & $59(42.8)$ & $27(41)$ & $32(44)$ & 0.67 & $170(28.9)$ & $87(29.4)$ & $83(28.4)$ & 0.82 & 0.002 \\
\hline Neoplastic disease & $6(4.3)$ & $4(6)$ & $2(3)$ & 0.34 & $43(7.3)$ & $23(7.8)$ & $20(6.8)$ & 0.68 & 0.21 \\
\hline Co-infections & $17(12.3)$ & $6(9)$ & $11(15)$ & 0.27 & $68(11.6)$ & $35(11.8)$ & $33(11.3)$ & 0.84 & 0.80 \\
\hline \multicolumn{10}{|l|}{ Diabetes-related variables } \\
\hline Glucose on admission, $\mathrm{mmol} / \mathrm{l}$ & $8.5 \pm 3.1$ & $8.6 \pm 3.2$ & $8.5 \pm 3.0$ & 0.85 & $6.8 \pm 2.2$ & $6.9 \pm 2.5$ & $6.5 \pm(1.6)$ & 0.052 & $<0.001$ \\
\hline Insulin pre-treatment & $45(33)$ & $21(32)$ & $24(33)$ & 0.85 & & & & & \\
\hline $\begin{array}{l}\text { Pre-treatment with oral glucose- } \\
\text { lowering agents }\end{array}$ & $99(72)$ & $51(77)$ & $48(67)$ & 0.17 & & & & & \\
\hline $\begin{array}{l}\text { Diabetes treatment with dietary } \\
\text { measures }\end{array}$ & $19(14)$ & $7(11)$ & $12(17)$ & 0.30 & & & & & \\
\hline $\mathrm{HbA}_{1 \mathrm{c}}, \%$ & & $7.4 \pm 1.4$ & $7.9 \pm 2.2$ & 0.31 & & & & & \\
\hline $\mathrm{HbA}_{1 \mathrm{c}}, \mathrm{mmol} / \mathrm{mol}$ & & $57.4 \pm 15.6$ & $62.8 \pm 24.2$ & & & & & & \\
\hline
\end{tabular}

Data are means $\pm \mathrm{SD}$ or $n(\%)$

${ }^{\text {a }}$ All diabetic patients compared with all non-diabetic patients

$\mathrm{SaO} 2$, arterial oxygen saturation 
Table 2 Overview of primary and secondary endpoints: diabetic vs non-diabetic patients

\begin{tabular}{|c|c|c|c|c|c|c|c|c|c|}
\hline \multirow[t]{2}{*}{ Endpoint } & \multicolumn{4}{|c|}{ Diabetic patients } & \multicolumn{4}{|c|}{ Non-diabetic patients } & \multirow{2}{*}{$\begin{array}{l}p \text { for } \\
\text { interaction }\end{array}$} \\
\hline & $\begin{array}{l}\text { Prednisone } \\
(n=66)\end{array}$ & $\begin{array}{l}\text { Placebo } \\
(n=72)\end{array}$ & $\begin{array}{l}\text { Regression } \\
\text { analysis, OR, } \\
\text { HR, coefficient } \\
(95 \% \mathrm{CI})\end{array}$ & $p$ value & $\begin{array}{l}\text { Prednisone } \\
(n=296)\end{array}$ & $\begin{array}{l}\text { Placebo } \\
(n=292)\end{array}$ & $\begin{array}{l}\text { Regression } \\
\text { analysis, OR, } \\
\text { HR, coefficient, } \\
(95 \% \text { CI })\end{array}$ & $p$ value & \\
\hline \multicolumn{10}{|l|}{ Primary endpoint } \\
\hline \multicolumn{10}{|l|}{ Secondary endpoints } \\
\hline $\begin{array}{l}\text { Time to effective } \\
\text { hospital } \\
\text { discharge, days }\end{array}$ & $8.6 \pm 5.4$ & $9.9 \pm 5.6$ & $\begin{array}{c}-1.31(-3.16 \\
0.54)^{\mathrm{b}}\end{array}$ & 0.16 & $7.5 \pm 6.0$ & $8.4 \pm 6.3$ & $-0.96(-1.95,0.04)^{\mathrm{b}}$ & 0.06 & 0.76 \\
\hline Death & $2(3)$ & $6(8)$ & $0.34(0.07,1.77)^{\mathrm{c}}$ & 0.18 & $14(4.7)$ & $7(2.4)$ & $2.02(0.80,5.08)^{\mathrm{c}}$ & 0.14 & 0.065 \\
\hline $\begin{array}{l}\text { Total duration of } \\
\text { antibiotic treatment, } \\
\text { days }\end{array}$ & $10.2 \pm 4.6$ & $9.9 \pm 3.8$ & $0.28(-1.16,1.71)^{\mathrm{b}}$ & 0.70 & $9.4 \pm 5.5$ & $10.0 \pm 5.2$ & $-0.60(-1.49,0.29)^{\mathrm{b}}$ & 0.18 & 0.38 \\
\hline $\begin{array}{l}\text { Intravenous antibiotic } \\
\text { treatment, days }\end{array}$ & $5.8 \pm 5.0$ & $6.6 \pm 4.9$ & $\begin{array}{c}-0.77(-2.46 \\
0.91)^{\mathrm{b}}\end{array}$ & 0.37 & $5.1 \pm 4.8$ & $6.0 \pm 4.9$ & $\begin{array}{c}-0.87(-1.67 \\
-0.06)^{\mathrm{b}}\end{array}$ & 0.035 & 0.92 \\
\hline CAP complications ${ }^{\mathrm{d}}$ & $1(2)$ & $4(6)$ & $0.26(0.03,2.30)^{\mathrm{c}}$ & 0.24 & $8(2.7)$ & $14(4.8)$ & $0.55(0.23,1.34)^{\mathrm{c}}$ & 0.19 & 0.54 \\
\hline $\begin{array}{l}\text { New insulin requirement } \\
\text { during hospitalisation }^{\text {e }}\end{array}$ & $34(76)$ & $32(67)$ & $1.92(0.77,4.81)^{\mathrm{c}}$ & 0.16 & $59(20)$ & $41(14)$ & $4.80(1.94,11.76)^{\mathrm{c}}$ & 0.001 & 0.16 \\
\hline $\begin{array}{l}\text { New insulin requirement } \\
\text { at day } 30\end{array}$ & $4(6)$ & $0(0)$ & - & - & $0(0.0)$ & $1(0.4)$ & - & - & - \\
\hline
\end{tabular}

Data are means $\pm \mathrm{SD}$ or $n(\%)$ unless otherwise stated

${ }^{\mathrm{a}} \mathrm{HR}$

${ }^{\mathrm{b}}$ Regression coefficient

${ }^{\mathrm{c}} \mathrm{OR}$

${ }^{\mathrm{d}}$ CAP complications: recurrence; acute respiratory distress syndrome; empyema; nosocomial infections until day 30; serious adverse events possibly related to CAP; ICU stay; re-admission to hospital

${ }^{\mathrm{e}}$ Includes only patients without prior insulin therapy ( $n=45$ in the prednisone group, $n=48$ in the placebo group)

( $p$ for interaction $=0.065 ;$ OR for diabetic patients $0.34[95 \%$ CI $0.07,1.77], p=0.18$; OR for non-diabetic patients 2.02 [95\% CI $0.80,5.08], p=0.14)$. We also performed a severity-adjusted analysis (adjusted for PSI), which showed similar effects for mortality (diabetic patients, OR 0.18 [95\% CI $0.03,1.27], p=0.09$ ); non-diabetic patients, OR 1.84 [95\% CI $0.69,4.88], p=0.22 ; p$ for interaction $=0.052$ ).

Time to effective hospital discharge, total duration of antibiotic treatment and the incidence of CAP complications did not differ between the treatment groups, either in diabetic or in non-diabetic patients. Also, duration of intravenous antibiotic treatment was reduced in non-diabetic patients, with no evidence for interaction. In diabetic patients treated with prednisone, four patients had new insulin requirement at day 30 . They were all pre-treated with oral glucose-lowering agents; their respective $\mathrm{HbA}_{1 \mathrm{c}}$ values at study inclusion ranged from $7.0 \%$ to $11.4 \%$ in the two different subgroups. No patients in the non-diabetic cohort treated with prednisone, but one previously non-diabetic patient in the placebo group, had new insulin requirement at day 30 .

Effect of corticosteroids on outcome in patients with vs without initial hyperglycaemia In both patients with and without hyperglycaemia on admission, TTCS was shorter in the prednisone group than in the placebo group without evidence for effect modification (ESM Table 1, $p$ for interaction $=$ $0.14)$. There were no significant differences in other secondary endpoints, although differences in mortality could not be compared due to the small number of patients in the subgroups.

Effect of corticosteroids on glucose levels Patients in the prednisone group had higher mean glucose levels and higher glycaemic variability during the study time as compared with patients in the placebo group (Table 3). This was found in both diabetic and non-diabetic patients, although diabetic patients had overall higher mean glucose levels. Furthermore, in the prednisone subgroup, more patients experienced hyperglycaemia during the study time ( $88 \%$ of diabetic and $52 \%$ of non-diabetic patients). Only $2.9 \%$ of the diabetic patients remained normoglycaemic during the study time with no significant difference between the prednisone and placebo group $(p=0.35)$. In non-diabetic patients, the proportion of normoglycaemic patients was significantly lower in the prednisone group (7.3\%) than in the placebo group $(29.7 \%, p<0.001)$.

Influence of corticosteroids on in-hospital insulin use In the group with diabetes, not previously treated with insulin, $76 \%$ 
of patients treated with prednisone required new insulin treatment during study time as compared with $67 \%$ of diabetic patients treated with placebo $(p=0.16)$ (Table 2). Within the non-diabetic subgroup, $20 \%$ of patients treated with prednisone and $14 \%$ of patients treated with placebo required new insulin therapy $(p=0.001)$. The interaction analysis showed no statistical significance $(p=0.16)$. Diabetic patients treated with prednisone did not require more additional insulin than diabetic patients treated with placebo, contrary to the findings in nondiabetic patients, in whom treatment with prednisone led to more additional insulin treatment (see ESM Table 2 for details).

\section{Effect of glucose levels and glucose variability on outcomes} We also investigated the association of overall mean glucose values and overall glucose variability with outcomes stratified by prednisone treatment. In unadjusted analysis, higher mean blood glucose was associated with longer TTCS only in the placebo group (OR 0.91 [95\% CI 0.85, 0.98], $p=0.012$ ), but not in the prednisone group (OR 0.98 [95\% CI 0.92, 1.03], $p=0.38$ ). Similarly, in patients with higher mean glucose levels, those treated with placebo had a longer hospital stay than those treated with prednisone (coefficient for placebo 0.63 [95\% CI 0.24, 1.02], $p=0.002 \mathrm{vs,} \mathrm{coefficient} \mathrm{for} \mathrm{predni-}$ sone 0.29 [95\% CI $-0.003,0.58], p=0.053$ ). However, after adjusting for PSI and for supplemental insulin, higher overall glucose levels did not influence the primary and secondary endpoints (Table 4 and ESM Table 3).

Higher glycaemic variability was associated with lower mortality in the prednisone group (PSI-adjusted OR 0.44 [95\% CI $0.22,0.88], p=0.02)$, Table 5). The effect on mortality remained significant after additional adjustment for insulin (OR adjusted for PSI and supplemental insulin 0.44 [95\% CI 0.22, 0.90], $p=0.03$ ). We repeated these analyses for the diabetic and the non-diabetic subgroups (see ESM Table 3 for higher mean glucose levels during study time and ESM Table 4 for higher glycaemic variability). Higher glycaemic variability in diabetic patients correlated with longer time to effective hospital discharge. This effect did not persist after adjusting for insulin treatment. Additionally, we found that in PSI-adjusted analysis, higher glycaemic variability was associated with reduced TTCS in non-diabetic patients and with lower mortality in diabetic patients, including both treatment groups. Both effects remained significant after additional adjustment for insulin.

\section{Discussion}

Our study has two key findings. First, the benefit of adjunct prednisone treatment in CAP patients with diabetes was similar across the overall population. This was valid for the

Table 3 Effect of corticosteroids on glucose levels

\begin{tabular}{|c|c|c|c|c|c|c|c|c|c|}
\hline \multirow{2}{*}{$\begin{array}{l}\text { Glycaemic } \\
\text { characteristic }\end{array}$} & \multicolumn{4}{|c|}{ Diabetic patients $(n=138)$} & \multicolumn{4}{|c|}{ Non-diabetic patients $(n=569)^{\mathrm{a}}$} & \multirow{2}{*}{$\begin{array}{l}p \\
\text { value }^{\mathrm{b}}\end{array}$} \\
\hline & All & $\begin{array}{l}\text { Prednisone } \\
(n=66)\end{array}$ & $\begin{array}{l}\text { Placebo } \\
(n=72)\end{array}$ & $\begin{array}{l}p \\
\text { value }\end{array}$ & All & $\begin{array}{l}\text { Prednisone } \\
(n=286)\end{array}$ & $\begin{array}{l}\text { Placebo } \\
(n=283)\end{array}$ & $\begin{array}{l}p \\
\text { value }\end{array}$ & \\
\hline $\begin{array}{l}\text { Mean glucose level } \\
\text { during study time, } \\
\mathrm{mmol} / \mathrm{c}^{\mathrm{c}}\end{array}$ & $9.64 \pm 2.46$ & $10.6 \pm 2.5$ & $8.8 \pm 2.1$ & $<0.001$ & $7.01 \pm 1.46$ & $7.6 \pm 1.6$ & $6.4 \pm 1.0$ & $<0.001$ & $<0.001$ \\
\hline $\begin{array}{l}\text { Glucose variability per } \\
\text { patient, } \mathrm{mmol} / \mathrm{l}^{\mathrm{c}}\end{array}$ & $3.04 \pm 1.45$ & $3.6 \pm 1.4$ & $2.5 \pm 1.3$ & $<0.001$ & $1.76 \pm 1.11$ & $2.3 \pm 1.1$ & $1.2 \pm 0.8$ & $<0.001$ & $<0.001$ \\
\hline $\begin{array}{l}\text { Normoglycaemia } \\
\quad \text { during study time }\end{array}$ & $4(2.9)$ & $1(2)$ & $3(4)$ & 0.35 & $105(18.5)$ & $21(7.3)$ & $84(29.7)$ & $<0.001$ & $<0.001$ \\
\hline $\begin{array}{l}\text { Hyperglycaemia during } \\
\text { study time }\end{array}$ & $110(79.7)$ & $58(88)$ & $52(72)$ & 0.022 & $204(35.9)$ & $149(52.1)$ & $55(19.4)$ & $<0.001$ & $<0.001$ \\
\hline $\begin{array}{l}\text { Elevated fasting } \\
\text { glucose levels }\end{array}$ & $15(10.9)$ & $2(3)$ & $13(18)$ & 0.005 & $157(27.6)$ & $49(17.1)$ & $108(38.2)$ & $<0.001$ & $<0.001$ \\
\hline $\begin{array}{l}\text { Elevated postprandial } \\
\text { glucose levels }\end{array}$ & $22(15.9)$ & $7(11)$ & $15(21)$ & 0.10 & $214(37.6)$ & $108(37.8)$ & $106(37.5)$ & 0.91 & $<0.001$ \\
\hline
\end{tabular}

Data are means $\pm \mathrm{SD}$ or $n(\%)$

${ }^{a}$ Nineteen non-diabetic patients had to be excluded from this analysis due to insufficient blood glucose measurements

${ }^{\mathrm{b}}$ All diabetic patients compared with all non-diabetic patients

${ }^{\mathrm{c}}$ As defined in methods

${ }^{\mathrm{d}}$ Every fasting blood glucose measurement was below $5.6 \mathrm{mmol} / 1$ and every postprandial blood glucose was below $7.8 \mathrm{mmol} / 1$

${ }^{\mathrm{e}}$ At least one blood glucose measurement was above $7.0 \mathrm{mmol} / 1$ preprandially or above $11.0 \mathrm{mmol} / 1$ postprandially

${ }^{\mathrm{f}}$ At least one fasting blood glucose of 5.6-7.0 mmol/1, never fulfilling criteria for hyperglycaemia

${ }^{\mathrm{g}}$ At least one postprandial blood glucose measurement of 7.8-11.0 mmol/1, never fulfilling criteria for hyperglycaemia. Thirteen diabetic and 91 nondiabetic patients had elevated fasting glucose levels as well as elevated postprandial glucose levels 
Table 4 Influence of higher overall glucose level on outcome

\begin{tabular}{|c|c|c|c|c|c|c|c|c|}
\hline \multirow[t]{3}{*}{ Endpoint } & \multicolumn{4}{|c|}{ Prednisone group $(n=352)^{\mathrm{b}}$} & \multicolumn{4}{|c|}{ Placebo group $(n=355)^{\mathrm{a}}$} \\
\hline & \multicolumn{2}{|l|}{ Adjusted for PSI } & \multicolumn{2}{|l|}{$\begin{array}{l}\text { Adjusted for PSI + } \\
\text { supplemental insulin }\end{array}$} & \multicolumn{2}{|l|}{ Adjusted for PSI } & \multicolumn{2}{|l|}{$\begin{array}{l}\text { Adjusted for PSI }+ \\
\text { supplemental insulin }\end{array}$} \\
\hline & $\begin{array}{l}\text { HR, OR, regression } \\
\text { coefficients }(95 \% \mathrm{CI})\end{array}$ & $p$ value & $\begin{array}{l}\text { HR, OR, regression } \\
\text { coefficients }(95 \% \mathrm{CI})\end{array}$ & $p$ value & $\begin{array}{l}\text { HR, OR, regression } \\
\text { coefficients }(95 \% \mathrm{CI})\end{array}$ & $p$ value & $\begin{array}{l}\mathrm{HR}, \mathrm{OR} \text {, regression } \\
\text { coefficients }(95 \% \mathrm{CI})\end{array}$ & $p$ value \\
\hline TTCS & $1.00(0.95,1.06)^{\mathrm{b}}$ & 0.92 & $1.01(0.95,1.10)^{\mathrm{b}}$ & 0.69 & $0.96(0.90,1.03)^{\mathrm{b}}$ & 0.32 & $1.00(0.91,1.10)^{\mathrm{b}}$ & 0.72 \\
\hline $\begin{array}{l}\text { Time to effective } \\
\text { hospital discharge }\end{array}$ & $0.07(-0.22,0.35)^{\mathrm{c}}$ & 0.65 & $0.03(-0.32,0.38)^{\mathrm{c}}$ & 0.88 & $0.30(-0.08,0.66)^{\mathrm{c}}$ & 0.13 & $0.23(-0.20,0.67)^{\mathrm{c}}$ & 0.29 \\
\hline Death & $0.88(0.67,1.17)^{\mathrm{d}}$ & 0.39 & $0.94(0.66,1.35)^{\mathrm{d}}$ & 0.75 & $0.94(0.65,1.36)^{\mathrm{c}}$ & 0.75 & $0.87(0.58,1.31)^{\mathrm{d}}$ & 0.52 \\
\hline $\begin{array}{l}\text { Total duration of } \\
\text { antibiotic } \\
\text { treatment }\end{array}$ & $-0.05(-0.32,0.22)^{\mathrm{c}}$ & 0.72 & $-0.06(-0.40,0.27)^{\mathrm{c}}$ & 0.71 & $-0.001(-0.33,0.33)^{\mathrm{c}}$ & 0.99 & $0.02(-0.37,0.41)^{\mathrm{c}}$ & 0.93 \\
\hline $\begin{array}{l}\text { Intravenous antibiotic } \\
\text { treatment }\end{array}$ & $-0.09(-0.33,0.15)^{\mathrm{c}}$ & 0.47 & $-0.09(-0.39,0.22)^{\mathrm{c}}$ & 0.58 & $0.08(-0.24,0.40)^{\mathrm{c}}$ & 0.62 & $0.02(-0.35,0.39)^{\mathrm{c}}$ & 0.91 \\
\hline CAP complications $^{\mathrm{e}}$ & $0.87(0.61,1.25)^{\mathrm{d}}$ & 0.46 & $1.00(0.73,1.61)^{\mathrm{d}}$ & 0.98 & $1.14(0.90,1.47)^{\mathrm{d}}$ & 0.30 & $1.20(0.87,1.64)^{\mathrm{d}}$ & 0.27 \\
\hline
\end{tabular}

We performed Cox regression analyses with the mean glucose level of every patient as a continuous variable

${ }^{a}$ Nineteen non-diabetic patients had to be excluded from this analysis due to insufficient blood glucose measurements

${ }^{\mathrm{b}} \mathrm{HR}$

${ }^{\mathrm{c}}$ Regression coefficient

${ }^{\mathrm{d}} \mathrm{OR}$

${ }^{\mathrm{e}} \mathrm{CAP}$ complications: recurrence; acute respiratory distress syndrome; empyema; nosocomial infections until day 30; serious adverse events possibly related to CAP; ICU stay; re-admission to hospital

primary endpoint TTCS, as well as for the secondary endpoints, without an increase in complications. Even though $76 \%$ of diabetic patients in the prednisone group required new insulin treatment during study time, as compared with $67 \%$ in the placebo group, only four diabetic patients treated with prednisone $(6 \%)$ required new insulin treatment at day

Table 5 Influence of higher glycaemic variability on outcome ${ }^{\mathrm{a}}$

\begin{tabular}{|c|c|c|c|c|c|c|c|c|}
\hline \multirow[t]{3}{*}{ Endpoint } & \multicolumn{4}{|c|}{ Prednisone group $(n=352)$} & \multicolumn{4}{|c|}{ Placebo group $(n=355)^{\mathrm{b}}$} \\
\hline & \multicolumn{2}{|l|}{ Adjusted for PSI } & \multicolumn{2}{|l|}{$\begin{array}{l}\text { Adjusted for PSI + } \\
\text { supplemental insulin }\end{array}$} & \multicolumn{2}{|l|}{ Adjusted for PSI } & \multicolumn{2}{|l|}{$\begin{array}{l}\text { Adjusted for PSI }+ \\
\text { supplemental insulin }\end{array}$} \\
\hline & $\begin{array}{l}\text { HR, OR, regression } \\
\text { coefficient }(95 \% \mathrm{CI})\end{array}$ & $p$ value & $\begin{array}{l}\text { HR, OR, regression } \\
\text { coefficient }(95 \% \mathrm{CI})\end{array}$ & $p$ value & $\begin{array}{l}\mathrm{HR}, \mathrm{OR}, \text { regression } \\
\text { coefficient }(95 \% \mathrm{CI})\end{array}$ & $p$ value & $\begin{array}{l}\text { HR, OR, regression } \\
\text { coefficient }(95 \% \mathrm{CI})\end{array}$ & $p$ value \\
\hline $\begin{array}{l}\text { Time to clinical } \\
\text { stability }\end{array}$ & $1.06(0.97,1.16)^{\mathrm{c}}$ & 0.17 & $1.09(0.98,1.21)^{\mathrm{c}}$ & 0.10 & $0.95(0.84,1.07)^{\mathrm{c}}$ & 0.40 & $1.00(0.86,1.16)^{\mathrm{c}}$ & 0.97 \\
\hline $\begin{array}{l}\text { Time to effective } \\
\text { hospital discharge }\end{array}$ & $0.25(-0.20,0.70)^{\mathrm{d}}$ & 0.28 & $0.27(-0.24,0.78)^{\mathrm{d}}$ & 0.31 & $0.52(-0.03,1.08)^{\mathrm{d}}$ & 0.06 & $0.51(-0.13,1.15)^{\mathrm{d}}$ & 0.12 \\
\hline Death & $0.44(0.22,0.88)^{\mathrm{e}}$ & 0.02 & $0.44(0.22,0.90)^{\mathrm{e}}$ & 0.03 & $0.90(0.43,1.89)^{\mathrm{e}}$ & 0.79 & $0.66(0.25,1.76)^{\mathrm{e}}$ & 0.41 \\
\hline $\begin{array}{l}\text { Total duration of } \\
\text { antibiotic treatment }\end{array}$ & $0.13(-0.33,0.60)^{\mathrm{d}}$ & 0.57 & $0.20(-0.32,0.73)^{\mathrm{d}}$ & 0.44 & $0.08(-0.41,0.57)^{\mathrm{d}}$ & 0.75 & $0.14(-0.43,0.71)^{\mathrm{d}}$ & 0.62 \\
\hline $\begin{array}{l}\text { Intravenous antibiotic } \\
\text { treatment }\end{array}$ & $-0.16(-0.58,0.26)^{\mathrm{d}}$ & 0.45 & $-0.12(-0.59,0.35)^{\mathrm{d}}$ & 0.61 & $0.24(-0.24,0.72)^{\mathrm{d}}$ & 0.33 & $0.21(-0.34,0.77)^{\mathrm{d}}$ & 0.45 \\
\hline CAP complications ${ }^{\mathrm{f}}$ & $0.78(0.42,1.43)^{\mathrm{e}}$ & 0.42 & $0.90(0.46,1.79)^{\mathrm{e}}$ & 0.77 & $1.14(0.75,1.75)^{\mathrm{e}}$ & 0.54 & $1.12(0.68,1.84)^{\mathrm{e}}$ & 0.66 \\
\hline
\end{tabular}

${ }^{a}$ As defined in the methods section. The mean glucose variability per patient was used as a continuous variable

${ }^{\mathrm{b}}$ Nineteen non-diabetic patients had to be excluded from this analysis due to insufficient blood glucose data

${ }^{\mathrm{c}} \mathrm{HR}$

${ }^{\mathrm{d}}$ Regression coefficient

${ }^{\mathrm{e}} \mathrm{OR}$

${ }^{\mathrm{f}} \mathrm{CAP}$ complications: recurrence, ARDS, empyema, nosocomial infections until day 30, possibly CAP-related SAE, ICU stay, rehospitalisation 
30. In at least three of these patients, this was not related to the corticosteroid medication itself but rather to the unsatisfactory metabolic status already existing before and at admission. We therefore consider the risk of diabetes progression due to a short-term corticosteroid intervention in the diabetic population to be negligible. This is in agreement with the few publications available on this topic, where complications of corticosteroid treatment are mainly seen during long-term treatment rather than in a short-term protocol of 7 days [24, 25]. Regarding mortality in the primary analysis, diabetic patients derived a greater benefit from prednisone treatment than nondiabetic patients, although this finding was not significant. Diabetic patients had a higher CAP severity. It is known that patients with a high CAP severity treated with corticosteroids experience less treatment failure [26] and show a better mortality reduction than patients with mild disease $[27,28]$. However, our finding cannot be related to CAP severity only, since results remained similar after adjustment for PSI.

The second main finding of our study was that overall mean glucose levels during hospitalisation and glucose variability were increased by prednisone treatment. Due to the hyperglycaemic effects of prednisone, there is concern about the impact of corticosteroid-induced hyperglycaemia on outcome. Accordingly, patients in the placebo group with a higher mean glucose and/or variability had a longer TTCS and prolonged time to effective hospital discharge. However, this effect did not persist after adjustment for disease severity and for supplemental insulin. Thus, hyperglycaemia in the overall population is likely a surrogate marker for disease severity and, hence, for outcome.

Previous studies investigating outcome prediction of admission and overall glucose levels in diabetic patients have shown similar results. Two studies showed that serum glucose levels on admission had no influence on outcome in diabetic CAP patients $[1,12]$ but that after adjusting for disease severity, persistent hyperglycaemia was an independent factor for worse outcome of CAP [12].

Contrarily, hyperglycaemia in patients treated with prednisone in our study (irrespective of diabetes status) did not have a negative effect on either primary or secondary endpoints.

Importantly, in diabetic patients, higher blood glucose values - reflecting a side-effect of prednisone - were not associated with a negative outcome. This finding persisted after adjustment for supplemental insulin. Possibly, diabetic patients are less sensitive to acute hyperglycaemic states and are hence protected from the toxic effects of high blood glucose levels [12]. Therefore, diabetic patients with CAP are an appropriate target group for adjunct prednisone treatment. Prednisone has a strong anti-inflammatory effect, modulating the immune system on a broad base towards restitution. Not only do corticosteroids play a crucial role in resolution of inflammation, they also enable an effective response to bacterial infections and tissue damage [29]. This is especially important in severe courses of CAP [30], which occur more often in diabetic patients.
The following limitations of the study have to be mentioned. First, as a secondary subgroup analysis, it may be underpowered for some comparisons due to smaller patient numbers in subgroups. Second, diagnosis of diabetes was based on medical records. There might have been undiagnosed diabetic patients potentially confounding the results. However, when we analysed subgroups of initial hyperglycaemia and normoglycaemia, we found the same results as in the subgroups of diabetic and non-diabetic patients. Third, we included patients hospitalised with CAP of any severity and patients with severe CAP were under-represented. Fourth, according to in-hospital guidelines, all patients with hyperglycaemia were treated. Based on our data, it is therefore not possible to conclude whether corticosteroid-induced hyperglycaemia should be treated or not.

In summary, our results show that the beneficial effect of adjunct prednisone in CAP on outcome was also valid for individuals with diabetes or hyperglycaemia upon hospital admission. Hyperglycaemia in diabetic patients or due to adjunct prednisone did not have a negative effect on outcome. For this reason, we advocate the use of corticosteroids as an appropriate additive treatment for CAP in patients with diabetes or hyperglycaemia on admission.

Acknowledgements We thank the members of the STEP Study Team (names and affiliations are listed in the ESM) for the patient recruitment and data organisation.

Funding This study was supported by a grant by the Swiss National Foundation (PP0P3 123346) to MCC and by the Nora van Meeuwen Häfliger Stiftung and the Gottfried Julia Bangerter-Rhyner Stiftung. $\mathrm{BM}, \mathrm{CAB}$ and PS were supported for this study by research funds from the Department of Endocrinology, Diabetology and Metabolism, Medical University Clinic of the Kantonsspital Aarau and the 'Argovia Professorship' of the Medical Faculty of the University of Basel.

Duality of interest The authors declare that there is no duality of interest associated with this manuscript.

Contribution statement MP and $\mathrm{CAB}$ collected, organised and interpreted the data, made substantial contributions to the concept and design and drafted the article. NN and BM contributed to the acquisition of the data and revised the manuscript critically. PS performed the statistical analyses and revised the paper critically. $\mathrm{MC}-\mathrm{C}$ made substantial contributions to the concept and design and revised the paper critically for intellectual content. All authors approved the final version to be published. MC-C and $\mathrm{CAB}$ had full access to all of the data in the study and take responsibility for the integrity of the data and the accuracy of the data analysis.

\section{References}

1. Lepper PM, Ott S, Nüesch E et al (2012) Serum glucose levels for predicting death in patients admitted to hospital for community acquired pneumonia: prospective cohort study. BMJ 344:e3397 
2. Yende S, van der Poll T, Lee M (2010) The influence of pre-existing diabetes mellitus on the host immune response and outcome of pneumonia: analysis of two multicentre cohort studies. Thorax 65 : 870-877

3. Falguera M, Pifarre R (2005) Etiology and outcome of communityacquired pneumonia in patients with diabetes mellitus. Chest 128 : 3233-3239

4. Fine M, Smith M, Carson C (1996) Prognosis and outcomes of patients with community-acquired pneumonia: a meta-analysis. JAMA 275:134-141

5. Kornum J, Thomsen R, Riis A (2007) Type 2 diabetes and pneumonia outcomes: a population-based cohort study. Diabetes Care 30:2251-2257

6. Saibal M, Rahman S (2013) Community acquired pneumonia in diabetic and non-diabetic hospitalized patients: presentation, causative pathogens and outcome. Bangladesh Med Res Counc Bull 38: 98-103

7. Valdez R, Narayan K (1999) Impact of diabetes mellitus on mortality associated with pneumonia and influenza among nonHispanic black and white US adults. Am J Public Health 89: $1715-1721$

8. Miyashita N, Matsushima T, Oka M (2006) The JRS guidelines for the management of community-acquired pneumonia in adults:an update and new recommendations. Intern Med 45:419-428

9. Lim WS, van der Eerden MM, Laing R et al (2003) Defining community acquired pneumonia severity on presentation to hospital: an international derivation and validation study. Thorax 58:377-382

10. Hirata Y, Tomioka H, Sekiya R (2013) Association of hyperglycemia on admission and during hospitalization with mortality in diabetic patients admitted for pneumonia. Intern Med 52:2431-2438

11. Bader M, Abouchehade K, Yi Y (2011) Antibiotic administration longer than eight hours after triage and mortality of communityacquired pneumonia in patients with diabetes mellitus. Eur J Clin Microbiol Infect Dis 30:881-886

12. Schuetz P, Friedli N, Grolimund E, Kutz A (2014) Effect of hyperglycaemia on inflammatory and stress responses and clinical outcome of pneumonia in non-critical-care inpatients: results from an observational cohort. Diabetologia 57:275-284

13. Leibovici L, Yehezkelli Y, Porter A (1996) Influence of diabetes mellitus and glycaemic control on the characteristics and outcome of common infections. Diabet Med 13:457-463

14. Becker T, Moldoveanu A (2007) Clinical outcomes associated with the use of subcutaneous insulin-by-glucose sliding scales to manage hyperglycemia in hospitalized patients with pneumonia. Diabetes Res Clin Pract 78:392-397

15. McAlister F, Majumdar S, Blitz S (2005) The relation between hyperglycemia and outcomes in 2,471 patients admitted to the hospital with community-acquired pneumonia. Diabetes Care 28:810 815
16. Meijvis SCA, Hardeman H, Remmelts HHF et al (2011) Dexamethasone and length of hospital stay in patients with community-acquired pneumonia: a randomised, double-blind, placebo-controlled trial. Lancet 377:2023-2030

17. Blum CA, Nigro N, Briel M et al (2015) Adjunct prednisone therapy for patients with community-acquired pneumonia: a multicentre, double-blind, randomised, placebo-controlled trial. Lancet 385:1511-1518

18. Blum C, Nigro N, Winzeler B (2014) Corticosteroid treatment for community-acquired pneumonia-the STEP trial: study protocol for a randomized controlled trial. Trials 15:257

19. Niederman MS, Mandell LA, Anzueto A et al (2001) Guidelines for the management of adults with community-acquired pneumonia. Diagnosis, assessment of severity, antimicrobial therapy, and prevention. Am J Respir Crit Care Med 163:1730-1754

20. Mandell LA, Wunderink RG, Anzueto A et al (2007) Infectious Diseases Society of America/American Thoracic Society consensus guidelines on the management of community-acquired pneumonia in adults. Clin Infect Dis 44(supp1 2):S27-S72

21. Fine M, Auble T, Yealy D (1997) A prediction rule to identify lowrisk patients with community-acquired pneumonia. N Engl J Med 336:243-250

22. Ali NA, O'Brien JM, Dungan K et al (2008) Glucose variability and mortality in patients with sepsis. Crit Care Med 36:2316-2321

23. Egi M, Bellomo R, Stachowski E et al (2006) Variability of blood glucose concentration and short-term mortality in critically ill patients. Anesthesiology 105:244-252

24. Reynolds R, Labad J, Sears A (2012) Glucocorticoid treatment and impaired mood, memory and metabolism in people with diabetes: the Edinburgh Type 2 Diabetes Study. Eur J Endocrinol 166:861868

25. Agustí C (2003) Pulmonary infiltrates in patients receiving longterm glucocorticoid treatment. Chest J 123:488

26. Torres A, Sibila O, Ferrer M et al (2015) Effect of corticosteroids on treatment failure among hospitalized patients with severe community-acquired pneumonia and high inflammatory response. JAMA 313:677

27. Siemieniuk RAC, Meade MO, Alonso-Coello P et al (2015) Corticosteroid therapy for patients hospitalized with communityacquired pneumonia. Ann Intern Med 163:519-528

28. Wan Y-D, Sun T-W, Liu Z-Q et al (2016) Efficacy and safety of corticosteroids for community-acquired pneumonia: a systematic review and meta-analysis. Chest 149:209-219

29. Busillo JM, Cidlowski JA (2013) The five Rs of glucocorticoid action during inflammation: ready, reinforce, repress, resolve, and restore. Trends Endocrinol Metab 24:109-119

30. Garcia-Vidal C, Calbo E, Pascual V et al (2007) Effects of systemic steroids in patients with severe community-acquired pneumonia. Eur Respir J 30:951-96 